\title{
Biomass-derived molecules modulate the behavior of Streptomyces coelicolor for antibiotic production
}

\author{
Shashi Kant Bhatia ${ }^{1,2} \cdot$ Bo-Rahm Lee ${ }^{1}$ Ganesan Sathiyanarayanan ${ }^{1} \cdot$

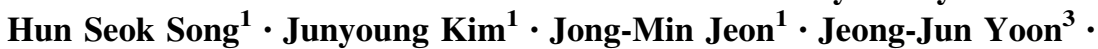 \\ Jungoh $\mathrm{Ahn}^{4} \cdot$ Kyungmoon Park ${ }^{5} \cdot$ Yung-Hun Yang ${ }^{1,2}$
}

Received: 1 August 2016/Accepted: 3 October 2016/Published online: 15 October 2016

(C) The Author(s) 2016. This article is published with open access at Springerlink.com

\begin{abstract}
Various chemicals, i.e., furfural, vanillin, 4-hydroxybenzaldehyde and acetate produced during the pretreatment of biomass affect microbial fermentation. In this study, effect of vanillin, 4-hydroxybenzaldehyde and acetate on antibiotic production in Streptomyces coelicolor is investigated. $I C_{50}$ value of vanillin, 4-hydroxybenzaldehyde and acetate was recorded as 5, 11.3 and $115 \mathrm{mM}$, respectively. Vanillin was found as a very effective molecule, and it completely abolished antibiotic (undecylprodigiosin and actinorhodin) production at $1 \mathrm{mM}$ concentration, while 4-hydroxybenzaldehyde and acetate have little effect. Microscopic analysis with field emission scanning electron microscopy (FESEM) showed that addition of vanillin inhibits mycelia formation and
\end{abstract}

Electronic supplementary material The online version of this article (doi:10.1007/s13205-016-0539-y) contains supplementary material, which is available to authorized users.

Yung-Hun Yang

seokor@konkuk.ac.kr

1 Department of Microbial Engineering, College of Engineering, Konkuk University, Seoul 143-701, South Korea

2 Institute for Ubiquitous Information Technology and Applications Konkuk University, Seoul 143-701, South Korea

3 IT Convergence Materials R\&BD Group, Chungcheong Regional Division, Korea Institute of Industrial Technology (KITECH), 35-3 Hongchon-ri, Ipjang-myun, Seobuk-gu, Chonan-si, Chungnam 330-825, South Korea

4 Biotechnology Process Engineering Center, Korea Research Institute Bioscience Biotechnology (KRIBB), Gwahangno, Yuseong-Gu, Daejeon 305-806, South Korea

5 Department of Biological and Chemical Engineering, Hongik University, Sejong Ro 2639, Jochiwon, Sejong, South Korea increases differentiation of S. coelicolor cells. Vanillin increases expression of genes responsible for sporulation $(\operatorname{ssg} A)$ and decreases expression of antibiotic transcriptional regulator (redD and actII-orf4), while it has no effect on genes related to the mycelia formation (bldA and bldN) and quorum sensing ( $s c b A$ and $s c b R$ ). Vanillin does not affect the glycolysis process, but may affect acetate and pyruvate accumulation which leads to increase in fatty acid accumulation. The production of antibiotics using biomass hydrolysates can be quite complex due to the presence of exogenous chemicals such as furfural and vanillin, and needs further detailed study.

Keywords Antibiotic - Biomass - Furfural - Streptomyces coelicolor · Vanillin

\section{Introduction}

Lignocellulose is a complex-structured biomass composed of cellulose, hemicelluloses, and lignin. It cannot be used as carbon source directly and it should be available as fermentable sugar (Bhatia et al. 2015a, 2016; Verma et al. 2016). Various pretreatment methods using acids (such as sulfuric acid and phosphoric acid) or bases (such as ammonium hydroxide, sodium hydroxide, and potassium hydroxide) have been reported to improve the accessibility of enzymes to the polysaccharides embedded inside the cell wall and to release free sugars (Laurens et al. 2015; Patel et al. 2012; Verma et al. 2013). Lignocellulose pretreatment using different methods also lead to the release of different inhibitors, i.e., furfural, vanillin, 4-hydroxybenzaldehyde, and acetate, which further affects the ability of microbes to utilize free sugar as a carbon source (Allen et al. 2010). Furfural and vanillin are more toxic

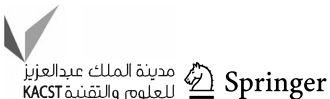


compounds beyond certain concentration and affect microbial growth (Zhang et al. 2014). A number of approaches have been used to investigate the mechanism of furfural action as this inhibits growth by damaging DNA and chemically reacting with cellular constituents (Akillioglu et al. 2011). Vanillin is one of the most prevalent phenolic compounds found in various lignocellulosic hydrolysates, e.g., from spruce, pine, poplar, corn stover and sugarcane bagasse, and acts as a quorum sensing (QS) blocker ( Lv et al. 2014).

Streptomyces coelicolor is a commercially important actinomycete having the potential to produce two chemically distinct pigments as secondary metabolite, i.e., actinorhodin (Act, diffusible blue pigment) and undecylprodigiosin (Red), a cell wall-associated red pigment (Bhatia et al. 2016; Gomez-Escribano and Bibb 2014). The production of antibiotics is regulated by nutrients, growth rate, quorum sensing, transcriptional regulators and other pleiotropic genes (Liu et al. 2013). Regulation is influenced by various low molecular mass compounds, transfer RNA, sigma factors and gene products formed during post-exponential development. These events generate signals which affect a cascade of regulatory events resulting in chemical differentiation (secondary metabolism) and morphological differentiation (morphogenesis). The transcriptional regulation of each antibiotic's biosynthetic gene cluster depends on a cluster-linked, antibiotic-specific and transcriptional regulator genes. Extensive classical and molecular genetic studies have led to the identification and characterization of numerous developmental genes, the bld and whi, and antibioticspecific regulators, actII-orf4 for Act and redD for Red (Bush et al. 2013; Lee et al. 2012; Price et al. 1999). Various genes responsible for the physiological controls which operate on pigment production in S. coelicolor are unknown. Molecular biology of antibiotic production is still not understood to a great degree and thus provides an opportunity for further investigation. Most of the research groups have reported that biomass-derived molecules act as an inhibitor, but interestingly in our previous research we found that furfural can elicit antibiotic production in $S$. coelicolor and it can be used to increase undecylprodigiosin production (Bhatia et al. 2016). Without considering various chemicals exist in biomass hydrolyzate, it is quite risky to use this as a carbon source. In this work, effect of other inhibitory molecules (vanillin, 4-hydroxybenzaldehyde and acetate) on antibiotic production and expression of various regulatory genes were studied.

\section{Materials and methods}

\section{Chemicals}

All the chemicals for media were purchased from Difco laboratories (Becton-Dickinson, Franklin Lakes, NJ, USA) and other chemicals, e.g., vanillin, 4-hydroxybenzaldehyde and acetate, were from Sigma-Aldrich (St. Louis, MO, USA). Agarose and bacterial agar were supplied by the Microbial carbohydrate resource bank at Konkuk University, Korea.

\section{Microorganism and seed culture}

Streptomyces coelicolor A3 (2) M145 used in this study for secondary metabolite production was purchased from the Korean Culture Type Collection (KCTC), South Korea. Streptomyces coelicolor spores were cultivated on R5 agar plates for $72 \mathrm{~h}$, harvested by scraping and suspended in $20 \%$ (v/v) glycerol and stored at $-80{ }^{\circ} \mathrm{C}$ (Kieser 2000). Streptomyces coelicolor seed culture was prepared by inoculating spores in $50 \mathrm{~mL}$ of $\mathrm{LB}$ liquid medium, with five glass beads of $3 \mathrm{~mm}$ size, and incubated at $30^{\circ} \mathrm{C}$ under shaking condition $(200 \mathrm{rpm})$. The germinated spores were harvested by centrifugation $\left(3200 \times g, 4{ }^{\circ} \mathrm{C}, 10 \mathrm{~min}\right)$ and resuspended in $5 \mathrm{~mL}$ of ion-free water. $0.1 \mathrm{~mL}(2 \times$ $\left.10^{6} \mathrm{CFU}\right)$ of germinated seed culture was used as inocula for further experiments in M9 minimal media of Difco laboratories with $1 \%$ glucose as carbon source.

\section{Antibiotic extraction and quantification}

For estimation of undecylprodigiosin (red) and actinorhodin (blue) antibiotics, $2 \mathrm{~mL}$ of culture samples was taken and divided into two aliquots. Actinorhodin estimation was performed by adding an equal volume of $1 \mathrm{M}$ $\mathrm{NaOH}$ into one of the aliquot, centrifuged for $5 \mathrm{~min}$ at $4000 \mathrm{~g}$, and absorbance was taken at $633 \mathrm{~nm}$. Undecylprodigiosin is a membrane-associated red pigment, so culture was harvested by centrifugation ( $4000 \mathrm{~g}$ for $5 \mathrm{~min}$ ) and cell pellet was suspended in methanol and incubated at $37{ }^{\circ} \mathrm{C}$ in a shaking incubator $(200 \mathrm{rpm})$ for $1 \mathrm{~h}$. Cells were removed by centrifugation at $4000 \mathrm{~g}$ for $5 \mathrm{~min}$; then $0.1 \mathrm{M} \mathrm{HCl}$ was added to the supernatant to adjust its $\mathrm{pH}$ and absorbance was measured at $533 \mathrm{~nm}$. The concentration of actinorhodin and undecylprodigiosin was calculated as described already (Horinouchi and Beppu 1984). 


\section{Inhibitors effect on $S$. coelicolor antibiotic} production

In this study, the effect of biomass-derived inhibitors, vanillin, 4-hydroxybenzaldehyde and acetate, was investigated on growth and secondary metabolite production in $S$. coelicolor. To check the effect of various inhibitors, $S$. coelicolor was cultured in M9 minimal media of Difco laboratories, with $1 \%$ glucose as carbon source and different concentrations of vanillin $(0-1 \mathrm{mM})$, 4-hydroxybenzaldehyde $(0-8 \mathrm{mM})$ and acetate $(0-80 \mathrm{mM})$, for $72 \mathrm{~h}$ at $30{ }^{\circ} \mathrm{C}$ under shaking condition $(200 \mathrm{rpm})$ at $10-\mathrm{mL}$ scale. After $72 \mathrm{~h}, 2 \mathrm{~mL}$ of the culture sample was taken and biomass and antibiotics, i.e., undecylprodigiosin (Red) and actinorhodin (Blue), were estimated as mentioned above.

\section{Field emission scanning electron microscopy (FESEM)}

Vanillin was observed as the most effective molecule which drastically changes the antibiotic production in $S$. coelicolor at very low concentration. To study the effect of this compound further, S. coelicolor was cultured using minimum effective concentration of vanillin $(1 \mathrm{mM})$ as mentioned above and monitored for morphological change. Samples were prepared for FESEM analysis using methods as already reported (Ishii et al. 2004). FESEM was performed by SUPRA 55VP, CarlZeiss, Oberkochen, Germany. The samples were monitored with a $15-\mathrm{kV}$ accelerating voltage and photographic images were captured digitally at different magnification.

\section{Lipids and metabolite quantification}

Antibiotic and fatty acid production pathways are interrelated (Revill et al. 1996), so total fatty acid of S. coelicolor cultured with and without vanillin was extracted and analyzed for composition as described already (Bhatia et al. 2015b). For metabolite analysis, S. coelicolor was cultured with vanillin at $30{ }^{\circ} \mathrm{C}$ for $72 \mathrm{~h}$. On completion of growth $1 \mathrm{~mL}$ of sample was collected, centrifuged at $12,000 \mathrm{~g}$ and supernatant was analyzed using an HPLC system equipped with a Bio-Rad Aminex HPX-87H column (Bio-Rad Co., Hercules, CA, USA). A mobile phase of $5 \mathrm{mM} \mathrm{H}_{2} \mathrm{SO}_{4}$ at a flow rate of $0.6 \mathrm{~mL} / \mathrm{min}$ was used and the column temperature was maintained at $50{ }^{\circ} \mathrm{C}$. Various organic acids were quantified at $210 \mathrm{~nm}$.

\section{Antibiotic regulatory genes study}

There are various genes of $S$. coelicolor already reported having a role in quorum sensing, secondary metabolite and morphology development, which altogether affects antibiotic production (Table 1). To study the mRNA expression level of these genes in the presence of vanillin, RT-PCR analysis was performed. For mRNA extraction, S. coelicolor spores were germinated for $5 \mathrm{~h}$ in LB broth at $30{ }^{\circ} \mathrm{C}$ and further used as seed. Streptomyces coelicolor culture was grown in the presence of vanillin $(1.0 \mathrm{mM})$ at $10-\mathrm{mL}$ scale for $72 \mathrm{~h}$ at $30{ }^{\circ} \mathrm{C}$ and samples were withdrawn at different time intervals. Collected samples were rapidly cooled on ice in pre-chilled Falcon tubes after which they were centrifuged at $4000 \mathrm{~g}$ for $10 \mathrm{~min}$ at $4{ }^{\circ} \mathrm{C}$. The supernatant was discarded and the pellet was added with $0.5 \mathrm{~mL}$ of RNA protect reagent (Qiagen, Valencia, CA, USA). The mixture was then incubated at $25^{\circ} \mathrm{C}$ for $5 \mathrm{~min}$. The RNeasy mini kit (Qiagen) was used for extracting total RNA from the control and vanillin-affected samples. The RNA was quantified using NanoDrop (Thermo Fisher Scientific, Waltham, MA, USA) by measuring the absorbance at 260 and $280 \mathrm{~nm}$. Super-script II reverse transcriptase kit (Invitrogen, Carlsbad, CA, USA) was used for cDNA synthesis from the extracted RNA.

\section{Reverse transcription polymerase chain reaction (RT-PCR)}

The primers specific for various genes and for the endogenous control (16S rRNA) were designed using the Primer Express software ${ }^{\circledR}$ (Applied Biosystems, Foster City, CA, USA) based on S. coelicolor genome published in the NCBI database. Custom-synthesized primers for each gene were obtained from Integrated DNA Technologies (Foster City, CA, USA). The primers used in the study are provided in Table 1. RT-PCR was done with the LifePro thermal cycler by custom thermal cycling conditions with the normalized cDNA as a template. The samples were analyzed in the duplicates and standardized against 16S rRNA gene expression. The relative changes in mRNA expression levels were determined using comparative band density between the vanillin and control $S$. coelicolor.

\section{Results and discussion}

\section{Effect of inhibitors on antibiotic production and morphology}

Furfural, vanillin, 4-hydroxybenzaldehyde and acetate are chemical molecules produced during the pretreatment of biomass (Allen et al. 2010). To know the effect of vanillin, 4-hydroxybenzaldehyde and acetate on antibiotic production in S. coelicolor, different concentrations were investigated. Vanillin had little effect on biomass production 
Table 1 Various genes targeted for the mRNA expression and primers designed for their amplification to study the effect of vanillin on their expression level

\begin{tabular}{|c|c|c|}
\hline Gene ID & Gene & Primer \\
\hline \multicolumn{3}{|c|}{ Antibiotic synthesis genes } \\
\hline SCO5877 & redD & $\begin{array}{l}\text { RT_redD_F: CCCGACAACGTCCTCAAC } \\
\text { RT_redD_R: CGAGACGAGTCTCAGGAAGC }\end{array}$ \\
\hline SCO5085 & actII-orf4 & $\begin{array}{l}\text { RT_actII4_F: AGAATAGGGCCGATGATTCC } \\
\text { RT_actII4_R: CCCAGTTCGTCGGACAGTAT }\end{array}$ \\
\hline \multicolumn{3}{|c|}{ Morphological genes } \\
\hline SCOt24 & bldA & $\begin{array}{l}\text { RT_bldA_F: GCCCGGATGGTGGAATGCAG } \\
\text { RT_bldA_R: TGGTGCCCGGAGCCGGACTT }\end{array}$ \\
\hline SCO3323 & $b l d N$ & $\begin{array}{l}\text { RT_bldN_F: CCTCGAGTCCCTCTCCAAC } \\
\text { RT_bldN_R: CGGTACTGGAGCGTTTTGAT }\end{array}$ \\
\hline SCO3926 & $\operatorname{ssg} A$ & $\begin{array}{l}\text { RT_ssgA_F: CCTTTCATCTGCCCGGAGAC } \\
\text { RT_ssgA_R: CGACCTGAAGTCGGATCAGC }\end{array}$ \\
\hline SCO1541 & $\operatorname{ssg} B$ & $\begin{array}{l}\text { RT_ssgB_F: TCGTGTGCATCGCTCTCAG } \\
\text { RT_ssgB_R: CTAGCTTTCCGCCAGGATGT }\end{array}$ \\
\hline SCO3925 & $s s g R$ & $\begin{array}{l}\text { RT_ssgR_F: GGCTGTTCTTCCTCGGTGAG } \\
\text { RT_ssgR_R: GAGACGCACATGACCTCGAT }\end{array}$ \\
\hline SCO2082 & fstz & $\begin{array}{l}\text { RT_ftsZ_F: GTTCATCGCCATCAACACCG } \\
\text { RT_ftsZ_R: TGTCACGAAGACCATGTCGG }\end{array}$ \\
\hline \multicolumn{3}{|c|}{ Quorum sensing and pleiotropic genes } \\
\hline SCO6266 & $s c b A$ & $\begin{array}{l}\text { RT_scbA_F: ACTACACCTGCCACCTCGAC } \\
\text { RT_scbA_R: GCCGGTAGACTTGAGGACTG }\end{array}$ \\
\hline SCO6265 & $s c b R$ & $\begin{array}{l}\text { RT_scbR_F: TCTTCGAGAAGCAGGGCTAC } \\
\text { RT_scbR_R: GCCCATGTCGATGAGTTCTT }\end{array}$ \\
\hline $\mathrm{SCO} 4425$ & $a f s S$ & $\begin{array}{l}\text { RT_afsS_F: ATGAGCGACAAGATGAAGGA } \\
\text { RT_afsS_R: GGTTGTCCATCGTGGTGAT }\end{array}$ \\
\hline SCO4426 & $a f_{s} R$ & $\begin{array}{l}\text { RT_afsR_F: GGCTGCTGGACTTCTACCTG } \\
\text { RT_afsR_R: CCTCCGTGTACAGCCAGTC }\end{array}$ \\
\hline
\end{tabular}

while a rapid decrease in antibiotic (undecylprodigiosin and actinorhodin) production was recorded with the increase of its concentration. There was no antibiotic production observed above $0.75 \mathrm{mM}$ vanillin (Fig. 1a). 4-Hydroxybenzaldehyde and acetate have a mild effect on biomass and antibiotic production in S. coelicolor (Fig. 1b, c). $I C_{50}$ value for vanillin, 4-hydroxybenzaldehyde and acetate was calculated as 5.0, 11.3 and $115 \mathrm{mM}$, respectively. Streptomyces coelicolor cells were cultured in the presence of various inhibitors at their $I C_{50}$ concentration and antibiotics (undecylprodigiosin and actinorhodin) were extracted. In the presence of vanillin, no antibiotic was observed; however, in case of 4-hydroxybenzaldehyde and acetate, reduction in both antibiotics' production was observed as compared to control (Fig. S1). Other biomassderived molecule such as furfural enhanced undecylprodigiosin production and inhibits actinorhodin production in $S$. coelicolor as already reported (Bhatia et al. 2016). In this study, vanillin was found as a most effective molecule which affected antibiotic production in S. coelicolor dramatically (Fig. S1). It was not easy to expect why this phenomena happened because there is no report on vanillin effect.

Among examined inhibitors, as vanillin showed inhibitory effects on antibiotic production at low concentration, any morphological change was further investigated. Field emission scanning electron microscopy (FESEM) of $S$. coelicolor cells cultured in the presence of vanillin was performed. Streptomyces coelicolor cells without any inhibitors showed normal mycelial growth and morphology (Fig. 2a). Streptomyces coelicolor cells grown in the presence of vanillin showed inhibition of mycelia formation (Fig. 2b), and cells had a round structure. In the presence of vanillin, $S$. coelicolor cells are unable to produce antibiotics due to the lack of mycelia. Mycelia formation is required for polyketide antibiotic production in $S$. coelicolor as already reported (Gehring et al. 2001). 
Fig. 1 Effect of biomassderived chemicals a vanillin, b 4-hydroxybenzaldehyde (4HB) and c acetate on $S$. coelicolor growth and antibiotic production. S. coelicolor was cultured in M9 media with $1 \%$ glucose and various concentrations of inhibitors
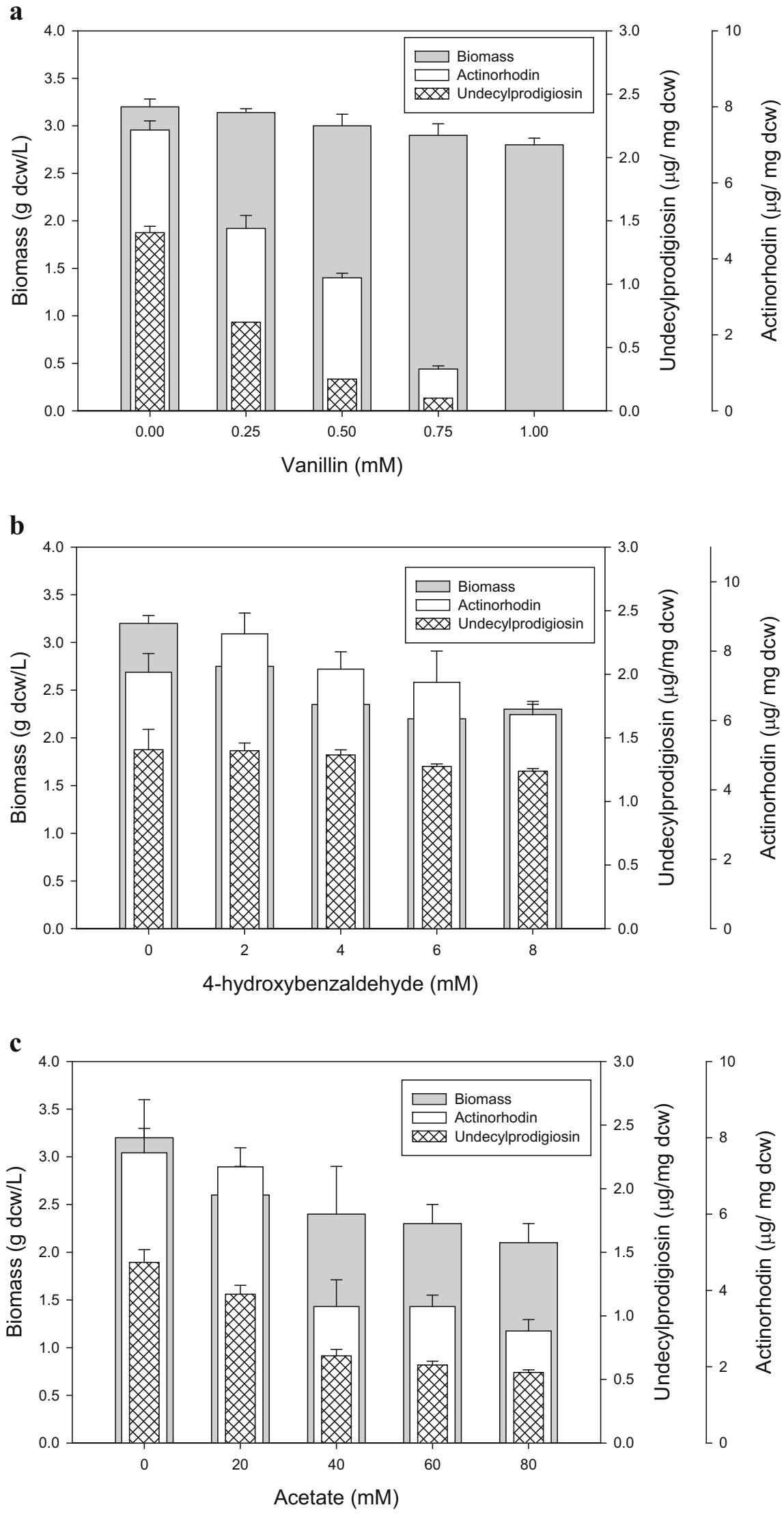
Fig. 2 Field emission scanning electron microscopy (FESEM) of $S$. coelicolor. a Control: normal cell morphology with mycelia; b with vanillin: cells are round shaped and mycelia formation is inhibited (a) Control
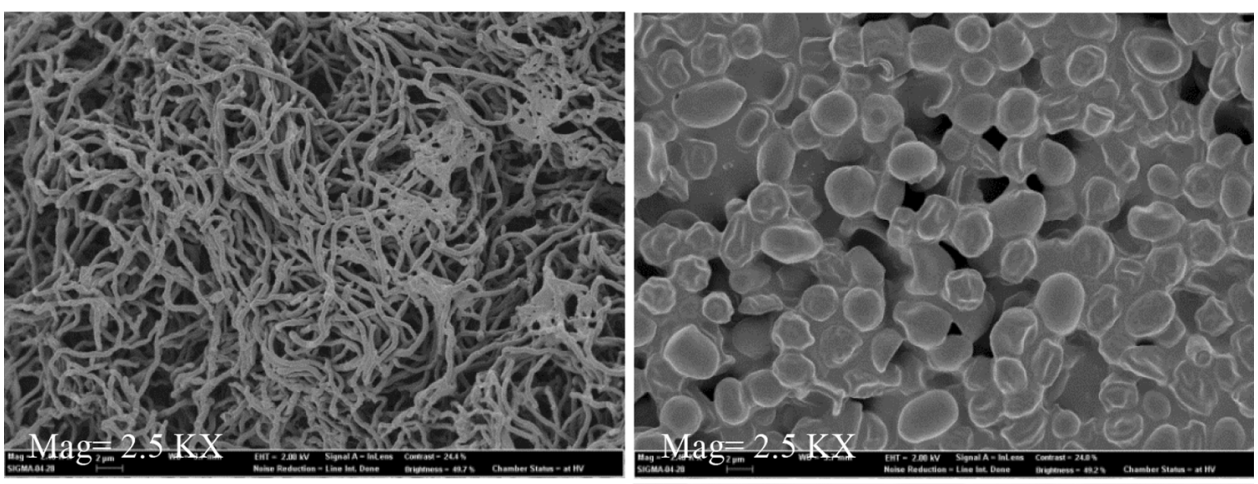

(b) Vanillin

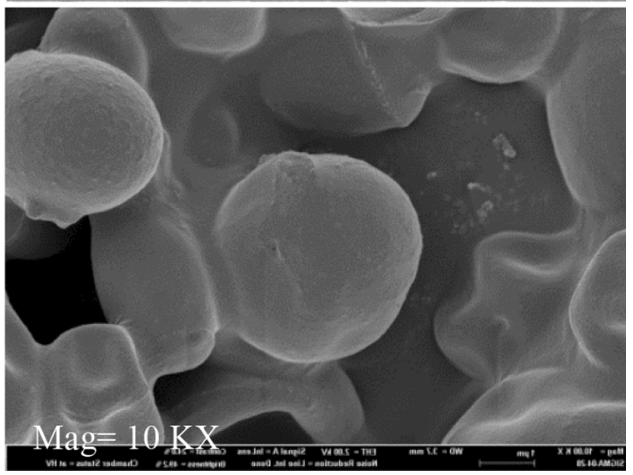

\section{Transcriptional analysis of antibiotic regulatory gene}

Streptomyces coelicolor cultured in the presence of vanillin completely abolished antibiotic production. mRNA expression profile of redD and actII-orf4 was analyzed at 48- and 72-h intervals and reduction in expression level was observed (Fig. S2), redD and actII-orf4 are transcriptional activator genes of the undecylprodigiosin and actinorhodin biosynthetic pathway, respectively, and regulate antibiotic production (Fujii et al. 1996; Wang et al. 2014). Bhatia et al. reported that increase in undecylprodigiosin and reduction in actinorhodin production in S. coelicolor under the effect of furfural is due to altered expression of redD and actII-orf4 (Bhatia et al. 2016). There was no change in the mRNA expression level of genes responsible for mycelia formation (bldA, bldN) analyzed in the presence of vanillin during all growth phases (Fig. S2). BldA has a role in mycelia development in $S$. coelicolor and it codes tRNA for leucine codon UUA required for undecylprodigiosin production at higher phosphate concentrations (White and Bibb 1997). BldN gene codes for sigma factor (BldN) required for the formation of specialized spore-bearing aerial hyphae during differentiation in the mycelial bacterium S. coelicolor (Bibb and Buttner 2003). Genes responsible for sporulation and differentiation of $S$. coelicolor were investigated for mRNA expression level. An increase in the $s s g A$ mRNA expression level (1.6-fold) was recorded. The $s s g A$ gene involved in cell division and development as already reported (van Wezel et al. 2000). Other genes responsible for sporulation, i.e., $s s g B, \operatorname{ssg} R$ and $f t s Z$, were not affected by vanillin (Fig. S2). Various genes involved in quorum sensing which may affect antibiotic production were also studied. Vanillin had no effect on $s c b A$ and $s c b R$ expression levels (Fig. S2). Change in $s c b A$ expression has no role in secondary metabolite production as already reported (D'Alia et al. 2011); an $s c b A$ mutant that failed to produce gamma-butyrolactones can still produce antibiotics, i.e., actinorhodin (Act) and undecylprodigiosin (Red). The decrease in $s c b R$ expression leads to a delay in undecylprodigiosin antibiotic production, as $s c b R$ failed to make gamma-butyrolactones (D'Alia et al. 2011). $A f_{S} S$ and $a f_{S} R$ are pleiotropic genes that regulate undecylprodigiosin and actinorhodin synthesis pathways (Horinouchi 2003; Lian et al. 2008). The increase in afsR copy number can stimulate both Act and Red production (Floriano and Bibb 1996), but no changes in the mRNA expression level of afs $S$ and $a f s R$ were recorded in the presence of vanillin. From mRNA expression data of morphological genes, it could be concluded that vanillin is affecting genes involved in sporulation and enhances differentiation of cells shown by FESEM analysis result. 
Table 2 Total fatty acid profile of $S$. coelicolor under the effect of vanillin

\begin{tabular}{lcc}
\hline Fatty acid & Control $(\%)$ & Vanillin $(\%)$ \\
\hline $\mathrm{C} 12: 0-3 \mathrm{OH}$ & $3.3 \pm 0.1$ & $4.6 \pm 0.4$ \\
$\mathrm{C} 14: 0-13 \mathrm{M}$ & $22.0 \pm 2.3$ & $18.3 \pm 3.4$ \\
$\mathrm{C} 15: 1$ & $2.0 \pm 0.2$ & $1.76 \pm 0.05$ \\
$\mathrm{C} 14: 0-2 \mathrm{OH}$ & $0.62 \pm 0.04$ & $0.49 \pm 0.02$ \\
$\mathrm{C} 14: 0-3 \mathrm{OH}$ & $29.2 \pm 4.0$ & $33.54 \pm 2.9$ \\
$\mathrm{C} 15: 0-14 \mathrm{M}$ & $3.0 \pm 0.07$ & $2.26 \pm 0.7$ \\
$\mathrm{C} 16: 1-\mathrm{n} 9$ & $19.0 \pm 3.3$ & $22.6 \pm 1.3$ \\
$\mathrm{C} 16: 0 \mathrm{cyclo}$ & $18.7 \pm 2.7$ & $14.30 \pm 2.1$ \\
$\mathrm{C} 16: 0-15 \mathrm{M}$ & $1.30 \pm 0.06$ & $1.0 \pm 0.06$ \\
$\mathrm{C} 16: 0-2 \mathrm{OH}$ & $0.45 \pm 0.02$ & $0.28 \pm 0.02$ \\
C18:3-n6,9,12 & $0.21 \pm 0.01$ & $0.58 \pm 0.04$ \\
C18:1-n9t & $0.36 \pm 0.05$ & $0.27 \pm 0.01$ \\
Total fatty acid $(\mu \mathrm{g} / \mathrm{mg} \mathrm{dcw})$ & $6.2 \pm 0.8$ & $19 \pm 2.3$ \\
\hline
\end{tabular}

\section{Total lipid and metabolite profiling}

Streptomyces coelicolor cells were cultured with and without inhibitors in the above-mentioned conditions. Streptomyces coelicolor without any inhibitors was able to accumulate fatty acid $(6.3 \mu \mathrm{g} / \mathrm{mg} \mathrm{dcw})$, while vanillin addition resulted in an increase in fatty acid accumulation (19 $\mu \mathrm{g} / \mathrm{mg} \mathrm{dcw)} \mathrm{(Table} \mathrm{2).} \mathrm{Vanillin} \mathrm{inhibited} \mathrm{antibiotic}$ production and resulted in an increase in fatty acid accumulation in $S$. coelicolor, as antibiotic and fatty acid synthesis pathways are interrelated (Revill et al. 1996). Metabolite concentrations in S. coelicolor culture supernatant were quantified at $72 \mathrm{~h}$. Glucose was consumed almost completely in control while $6 \%$ reduction in glucose utilization was recorded in the presence of vanillin. Increase in acetate $(2.6 \mathrm{mM})$ and pyruvate $(4.7 \mathrm{mM})$ accumulation was observed in the presence of vanillin (Fig. S3). This observation suggests that glycolysis pathway of $S$. coelicolor in control and vanillin-treated cell is working properly as there was little change in glucose consumption. Vanillin represses the expression of antibiotic synthesis genes and enhances acetate accumulation which further reduces antibiotic production as observed above with the external addition of acetate. Organic acid content, i.e., acetate and pyruvate, affects the $\mathrm{pH}$ of fermentation broth which further changed antibiotic synthesis in S. coelicolor as already explained (Yang et al. 2010).

\section{Conclusion}

Biomass is an abundantly available raw material and can be used to develop an economic bioprocess for the production of industrial valuable compounds. Use of biomass hydrolysate without knowing its composition may lead to adverse effects on microbial fermentation and productivity. Cultivation of $S$. coelicolor in the presence of biomassderived molecules affects metabolite pool and morphology of $S$. coelicolor, which further leads to change in antibiotic production. Microbes show different behavior against each inhibitory compound; therefore, there is a need to study the role of such type of compounds to use biomass as a potential carbon source.

Acknowledgments The study was supported by the National Research Foundation of Korea (NRF) funded by the Ministry of Education (NRF-2015R1A2A2A04006014) and (NRF2015M1A5A1037196), R\&D Program of MOTIE/KEIT (10048350, 10049674), Korea Institute of Energy Technology Evaluation and Planning (KETEP), and the Ministry of Trade, Industry \& Energy (MOTIE) of the Republic of Korea (No. 20163010092150). This article was also supported by the KU research Professor Program and KU Brain Pool Fellowship Program of Konkuk University, Seoul, South Korea.

\section{Compliance with ethical standards}

Conflict of interest The authors declare that they have no conflict of interest.

Open Access This article is distributed under the terms of the Creative Commons Attribution 4.0 International License (http:// creativecommons.org/licenses/by/4.0/), which permits unrestricted use, distribution, and reproduction in any medium, provided you give appropriate credit to the original author(s) and the source, provide a link to the Creative Commons license, and indicate if changes were made.

\section{References}

Akillioglu HG, Mogol BA, Gokmen V (2011) Degradation of 5-hydroxymethylfurfural during yeast fermentation. Food Addit Contam Part A Chem Anal Control Expo Risk Assess 28:1629-1635. doi:10.1080/19440049.2011.609491

Allen SA et al (2010) Furfural induces reactive oxygen species accumulation and cellular damage in Saccharomyces cerevisiae. Biotechnol Biofuels 3:1-10. doi:10.1186/1754-6834-3-2

Bhatia SK, Kumar N, Bhatia RK (2015a) Stepwise bioprocess for exopolysaccharide production using potato starch as carbon source. 3 Biotech 5:735-739. doi:10.1007/s13205-014-0273-2

Bhatia SK et al (2015b) Development of semi-synthetic microbial consortia of Streptomyces coelicolor for increased production of biodiesel (fatty acid methyl esters). Fuel 159:189-196. doi:10. 1016/j.fuel.2015.06.084

Bhatia SK et al (2016) Medium engineering for enhanced production of undecylprodigiosin antibiotic in Streptomyces coelicolor using oil palm biomass hydrolysate as a carbon source. Bioresour Technol 27:30182-30188. doi:10.1016/j.biortech. 2016.02.055

Bibb MJ, Buttner MJ (2003) The Streptomyces coelicolor developmental transcription factor sigmaBldN is synthesized as a proprotein. J Bacteriol 185:2338-2345. doi:10.1128/JB.185.7. 2338-2345.2003

Bush MJ, Bibb MJ, Chandra G, Findlay KC, Buttner MJ (2013) Genes required for aerial growth, cell division, and chromosome 
segregation are targets of WhiA before sporulation in Streptomyces venezuelae. mBio. doi:10.1128/mBio.00684-13

D’Alia D, Eggle D, Nieselt K, Hu WS, Breitling R, Takano E (2011) Deletion of the signalling molecule synthase ScbA has pleiotropic effects on secondary metabolite biosynthesis, morphological differentiation and primary metabolism in Streptomyces coelicolor A3(2). Microb Biotechnol 4:239-251. doi:10. 1111/j.1751-7915.2010.00232.x

Floriano B, Bibb M (1996) afsR is a pleiotropic but conditionally required regulatory gene for antibiotic production in Streptomyces coelicolor A3(2). Mol Microbiol 21:385-396. doi:10. 1046/j.1365-2958.1996.6491364.x

Fujii T, Gramajo HC, Takano E, Bibb MJ (1996) redD and actIIORF4, pathway-specific regulatory genes for antibiotic production in Streptomyces coelicolor A3(2), are transcribed in vitro by an RNA polymerase holoenzyme containing sigma hrdD. J Bacteriol 178:3402-3405. https://www.ncbi.nlm.nih.gov/ pubmed/8655533

Gehring AM, Yoo NJ, Losick R (2001) RNA polymerase sigma factor that blocks morphological differentiation by Streptomyces coelicolor. J Bacteriol 183:5991-5996. doi:10.1128/JB.183.20. 5991-5996.2001

Gomez-Escribano JP, Bibb MJ (2014) Heterologous expression of natural product biosynthetic gene clusters in Streptomyces coelicolor: from genome mining to manipulation of biosynthetic pathways. J Indus Microbiol Biotechnol 41:425-443. doi:10. 1007/s10295-013-1348-5

Horinouchi S (2003) AfsR as an integrator of signals that are sensed by multiple serine/threonine kinases in Streptomyces coelicolor A3(2). J Indus Microbiol Biotechnol 30:462-467. doi:10.1007/ s10295-003-0063-z

Horinouchi S, Beppu T (1984) Production in large quantities of actinorhodin and undecylprodigiosin induced by afsB in Streptomyces lividans. Agric Biol Chem 48:2131-2133. doi:10.1271/ bbb1961.48.2131

Ishii S, Koki J, Unno H, Hori K (2004) Two morphological types of cell appendages on a strongly adhesive bacterium, Acinetobacter sp. strain Tol 5. Appl Environ Microbiol 70:5026-5029. doi:10. 1128/AEM.70.8.5026-5029.2004

Kieser T (2000) Practical streptomyces genetics. John Innes Foundation. https://www.jic.ac.uk/science/molmicro/Strepmanual/ Manual.htm. Accessed 5 July 2016

Laurens LML, Nagle N, Davis R, Sweeney N, Van Wychen S, Lowell A, Pienkos PT (2015) Acid-catalyzed algal biomass pretreatment for integrated lipid and carbohydrate-based biofuels production. Green Chem 17:1145-1158. doi:10.1039/c4gc01612b

Lee HN, Kim HJ, Kim P, Lee HS, Kim ES (2012) Minimal polyketide pathway expression in an actinorhodin cluster-deleted and regulation-stimulated Streptomyces coelicolor. J Ind Microbiol Biotechnol 39:805-811. doi:10.1007/s10295-011-1083-8

Lian W et al (2008) Genome-wide transcriptome analysis reveals that a pleiotropic antibiotic regulator, AfsS, modulates nutritional stress response in Streptomyces coelicolor A3(2). BMC Genom 9:1471-2164. doi:10.1186/1471-2164-9-56

Liu G, Chater KF, Chandra G, Niu G, Tan H (2013) Molecular regulation of antibiotic biosynthesis in streptomyces. Microbiol Mol Biol Rev 77:112-143. doi:10.1128/MMBR.00054-12

Lv J, Wang Y, Zhong C, Li Y, Hao W, Zhu J (2014) The effect of quorum sensing and extracellular proteins on the microbial attachment of aerobic granular activated sludge. Bioresour Technol 152:53-58. doi:10.1016/j.biortech.2013.10.097

Patel SK, Singh M, Kumar P, Purohit HJ, Kalia VC (2012) Exploitation of defined bacterial cultures for production of hydrogen and polyhydroxybutyrate from pea-shells Biomass Bioenerg 36:218-225. doi:10.1016/j.biombioe.2011.10.027

Price B, Adamidis T, Kong R, Champness W (1999) A Streptomyces coelicolor antibiotic regulatory gene, absB, encodes an RNase III homolog. J Bacteriol 181:6142-6151. https://www.ncbi.nlm. nih.gov/pubmed/10498729. Accessed 7 July 2016

Revill WP, Bibb MJ, Hopwood DA (1996) Relationships between fatty acid and polyketide synthases from Streptomyces coelicolor A3(2): characterization of the fatty acid synthase acyl carrier protein. J Bacteriol 178:5660-5667. https://www.ncbi.nlm.nih. gov/pmc/articles/PMC178404/. Accessed 9 July 2016

van Wezel GP, van der Meulen J, Kawamoto S, Luiten RG, Koerten HK, Kraal B (2000) ssgA is essential for sporulation of Streptomyces coelicolor A3(2) and affects hyphal development by stimulating septum formation. J Bacteriol 182:5653-5662. https://www.ncbi.nlm.nih.gov/pmc/articles/PMC94684/. Accessed 7 July 2016

Verma ML, Rajkhowa R, Wang X, Barrow CJ, Puri M (2013) Exploring novel ultrafine Eri silk bioscaffold for enzyme stabilisation in cellobiose hydrolysis. Bioresour Technol 145:302-306. doi:10.1016/j.biortech.2013.01.065

Verma ML, Puri M, Barrow CJ (2016) Recent trends in nanomaterials immobilised enzymes for biofuel production. Crit Rev Biotechnol 36:108-119. doi:10.3109/07388551.2014.928811

Wang W et al (2014) Angucyclines as signals modulate the behaviors of Streptomyces coelicolor. Proc Natl Acad Sci USA 111:5688-5693. doi:10.1073/pnas.1324253111

White J, Bibb M (1997) bldA dependence of undecylprodigiosin production in Streptomyces coelicolor A3(2) involves a pathwayspecific regulatory cascade. J Bacteriol 179:627-633. https:// www.ncbi.nlm.nih.gov/pmc/articles/PMC178740/. Accessed 5 July 2016

Yang YH et al (2010) Rapid functional screening of Streptomyces coelicolor regulators by use of a $\mathrm{pH}$ indicator and application to the MarR-like regulator AbsC. Appl Environ Microbiol 76:3645-3656. doi:10.1128/AEM.02617-09

Zhang S, Winestrand S, Guo X, Chen L, Hong F, Jonsson LJ (2014) Effects of aromatic compounds on the production of bacterial nanocellulose by Gluconacetobacter xylinus. Microb Cell Fact 13:1475-2859. doi:10.1186/1475-2859-13-62 